\title{
Study the Urban Expansion of Taif City Using Remote Sensing and GIS Techniques for Decision Support System
}

\author{
Bader Alharthi1 ${ }^{*}$, Tarek A. El-Damaty ${ }^{2}$ \\ ${ }^{1}$ Department of Civil and Architectural Technology, Taif Technical College, Technical and Vocational Training Corporation, Taif, \\ Saudi Arabia \\ ${ }^{2}$ Department of Civil Engineering, Faculty of Engineering and Islamic Architecture, Umm Al-Qura University, Makkah, Saudi \\ Arabia \\ Email: ^ba4442@hotmail.com, tdamaty@hotmail.com
}

How to cite this paper: Alharthi, B. and El-Damaty, T.A. (2022) Study the Urban Expansion of Taif City Using Remote Sensing and GIS Techniques for Decision Support System. Advances in Remote Sensing, 11, 1-15.

https://doi.org/10.4236/ars.2022.111001

Received: January 15, 2022

Accepted: February 26, 2022

Published: March 1, 2022

Copyright (C) 2022 by author(s) and Scientific Research Publishing Inc. This work is licensed under the Creative Commons Attribution International License (CC BY 4.0).

http://creativecommons.org/licenses/by/4.0/

\section{Abstract}

The goal of this study is to spatially portray Taif's urban expansion and determine for last 30 years, from 1990 to 2020. It is only including the residential neighborhoods approved by the Taif Municipality, which is responsible and organized for urban planning in the city. The geographical location of the city of Taif is a vital crossroad between eastern and western parts of the Kingdom of Saudi Arabia, which made it a tourist destination, as well as commercial and agricultural preference for many years, as it was considered the summer capital of the KSA. Moreover, it serves as the entrance to Makkah city from the eastern side. The proposed study has necessitated because the lack of recent scientific studies that dealt with the spatial analysis of urban expansion and its trends in the city of Taif and follow the stages of expansion during periods of time by relying on remote sensing and geographic information systems (GIS) techniques. The many development projects in the city of Taif, such as Taif International Airport, the new Taif project, and other projects, which will cause an increase in demand for residential, commercial, industrial and service units have also prompted the proposed study. This was investigated using a multitemporal Landsat data for the years of 1990, 2002 and 2020, as well as census data from 1990 to 2020, along with Remote Sensing (RS) and Geographic Information System (GIS) techniques. The results revealed that over the last 30 years, urban land cover has increased by 20,448 (ha) whereas other land covers, such as green area, have decreased significantly by 14,554 (ha). The results also indicate that the increase in urban areas amounted to $114.8 \%$ during the period from 1990 to 2020 . The locations of new developments such as Taif airport, Taif university, Ministry of Housing projects, etc. were located to the North and Northeast. This is due to 
the area's topography, which played a major role in determining the direction of urban expansion. According to the study, multiple urban centers, rising low-density dispersed communities, and leapfrogging growth were all hallmarks of urban expansion in Taif. The study demonstrated that Taif is at risk of ecosystem loss as a result of continued urban expansion. To ensure environmental sustainability, the current effort asks for actions that will restrict urban sprawl and prepare the city for future growth.

\section{Keywords}

Remote Sensing, Land Use and Land Cover (LU/LC), Landsat Image, Image Classification, Urban Growth, Taif

\section{Introduction}

The Kingdom of Saudi Arabia (KSA) has witnessed rapid urbanization since 1950 , with increased the population in urban regions has from $21 \%$ in 1950 , through $58 \%$ in 1975 , to $83 \%$ in 2015 , and is estimated to reach $86 \%$ by 2030 [1]. In terms of population, the city of Taif is the sixth largest city in the Kingdom and also the third city in the Makkah region. In 1990, Taif's population was 381,000 people, and by 2020 , it grew to over 689,000 people, with a growth rate of $2 \%$ per annum [2]. There are more than 1000 villages around Taif, about 100 $\mathrm{km}$ south of the city [3]. Most of their population moved to urban area to search for economic opportunities especially young people. This is considered one of the most important reasons for the increase in the population of Taif city. However, it is very important to create a balance between human development and the protection of the environment for sustainability. Urban growth creates economic and social opportunities but may affect the ecosystem and lose biodiversity [4]. Thus, there is a benefit in assessing the Taif's city spatial urban growth pattern and examining its impact on different ecosystems. The main objectives of this study are: 1) study urban expansion of Taif city footprint in the last 30 years, 2) study the impact of the region's topography on urban expansion, and 3) study the role of the government in urban expansion in Taif. In addition, the purpose of this study is to evaluate urban expansion of Taif city for last 30 years, from 1990 to 2020. The results will show the proportion and direction of urban expansion to assess the city's urban planners. Hopefully, the results of this research will provide policy-makers and city planners with valuable information for future planning. Additionally, this research will make contributions to research on emerging technology for urban making plans and management and as a device for advancing the sustainable improvement of cities and urban areas.

\section{Study Area}

The name Taif means "encompassing" in Arabic [5]. It is a magnet that draws 


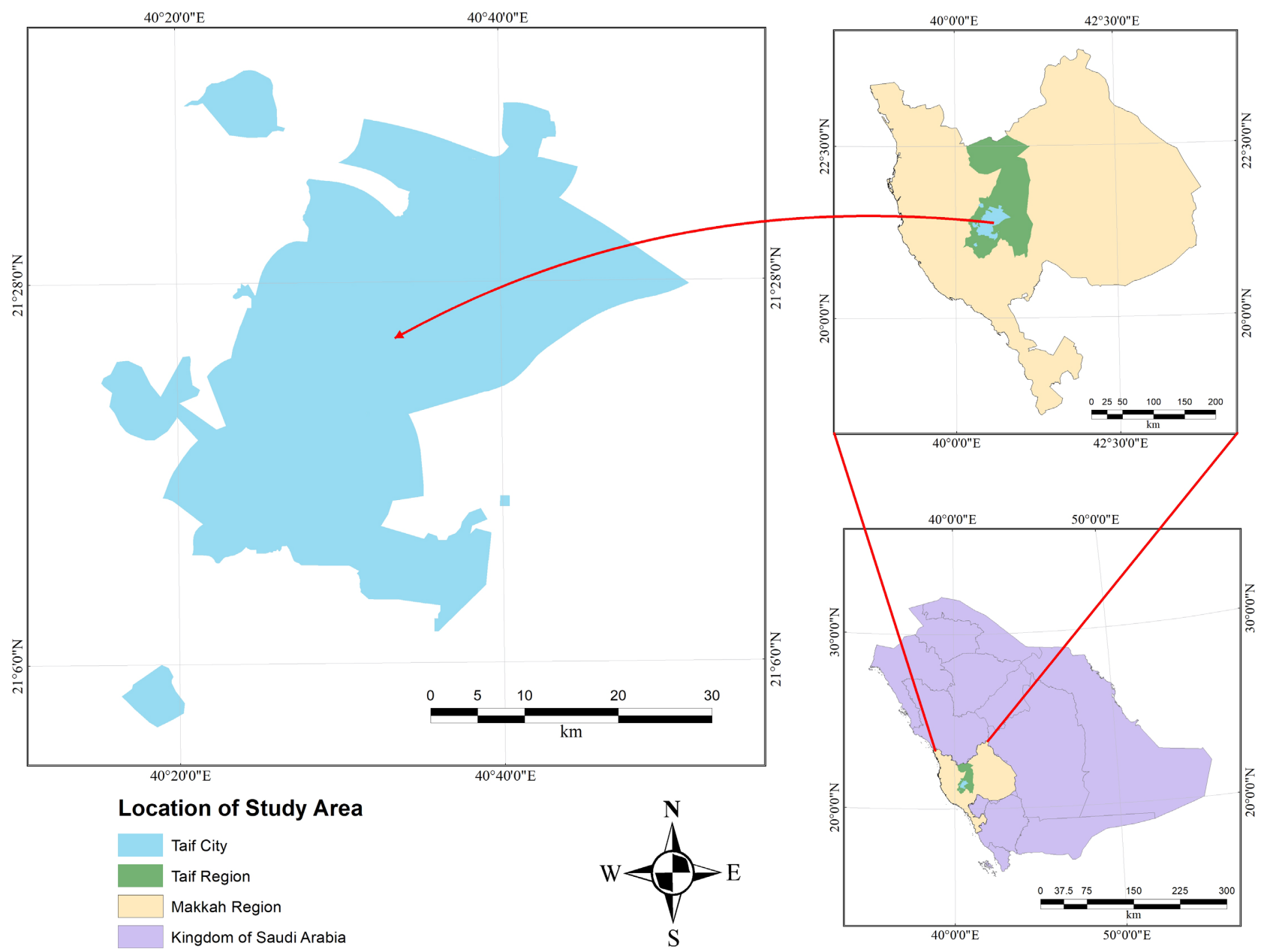

Figure 1. Location of study area.

visitors from across Saudi Arabia by its a pleasant climate [6] [7], which has become the official summer capital of the country. It is located west of Saudi Arabia, on the eastern slopes of the Sarawat Mountains, and it is one of the largest governorates of the Makkah Region in terms of area. It stands at an elevation of 1800 meters above sea level. The geographic extent of Taif city is $21^{\circ} 20^{\prime}$ to $21^{\circ} 41^{\prime} \mathrm{N}$ and $40^{\circ} 15^{\prime}$ to $40^{\circ} 52^{\prime} \mathrm{E}$, as shown in Figure 1.

\section{Materials and Methods}

\subsection{Topography of Area}

The geology of Taif is characterized by the fact that they are mountainous rocks. However, Taif city is subdivided into two distinct regions, a mountainous region in the west and in the southwest, and a desert region in the northeastern and eastern parts of the city. There are also more than 400 mountain peaks in the province, varying in height and size, and most of them are concentrated in the western and southern parts of Taif. The highest peak is Mount Dhaka, 2585 meters above sea level. Generally, Taif is located at an average elevation of 1800 meters above sea level. The present study utilized Shuttle Radar Topographic 
Mission (SRTM) digital elevation model (DEM) with 1 arc-second resolution (30 meters) to show the topography of Taif, which can be seen in Figure 2.

\subsection{Population Data}

Population growth and population density are important factors for urban studies, which help to explain many changes that occur in the region. The population of any area affects the city's environment and the land use. Migration from the countryside is also considered one of the most important reasons for continuous urban growth. The population in Taif city was 381,000 in 1990. In 2010, the population of the city of Taif was 582,000 people, according to the population census approved by the General Authority for Statistics. At the present time, the population of Taif city is expected to reach 689,000 people, and expected to reach 775,000 in the next ten years. Table 1 clearly shows that in the last 30 years, the population of the city increased by $80.8 \%$. Figure 3 , is a map of the population density in Taif city.
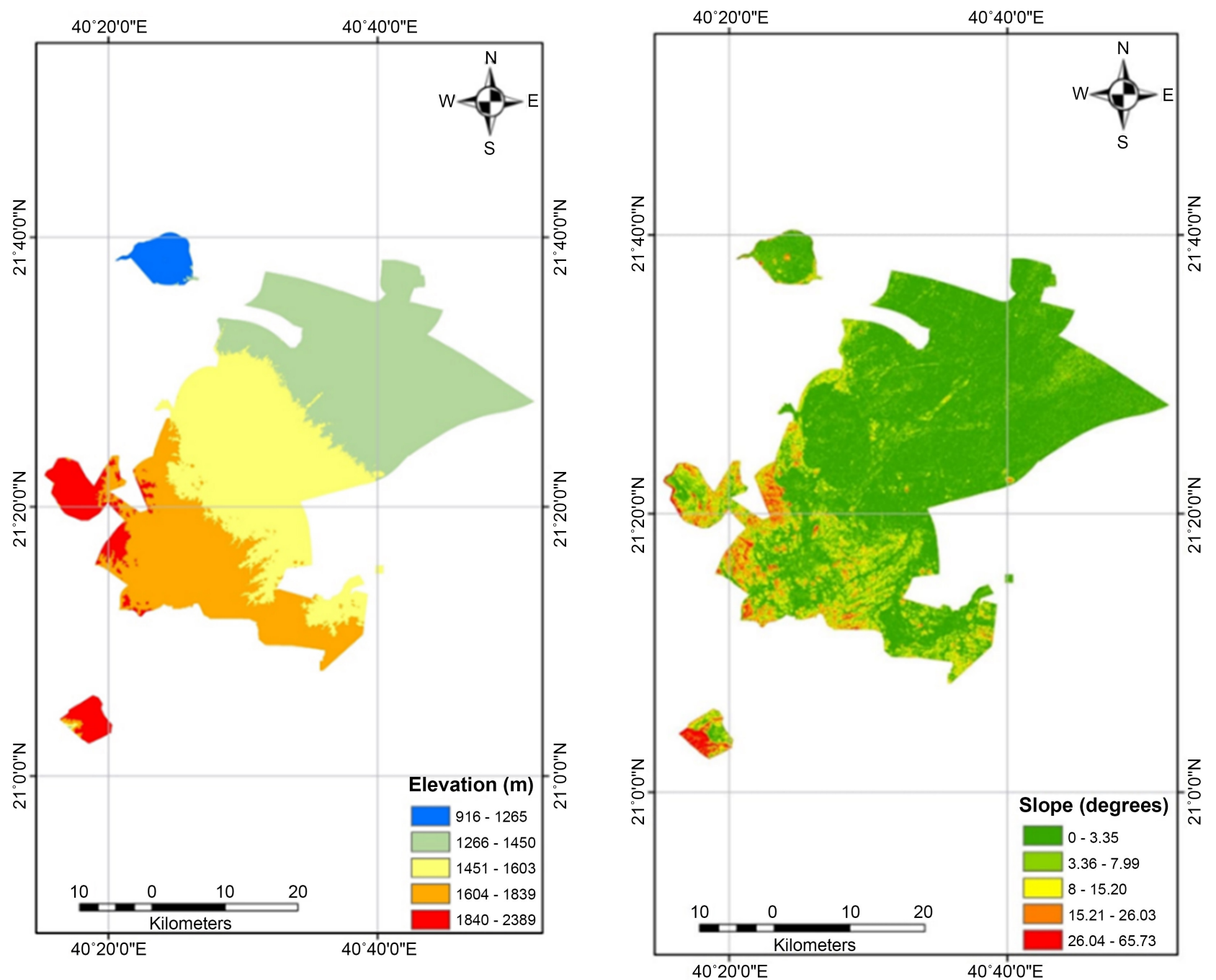

Figure 2. Topography of Taif city. 
Table 1. Population rate (Population stat, 2020).

\begin{tabular}{ccc}
\hline Year & Population & Growth Rate \\
\hline 1990 & 381,000 & - \\
1995 & 438,000 & 2.82 \\
2000 & 482,000 & 1.92 \\
2005 & 529,000 & 1.88 \\
2010 & 582,000 & 1.92 \\
2015 & 640,000 & 1.92 \\
2020 & 689,000 & 1.49 \\
\hline
\end{tabular}

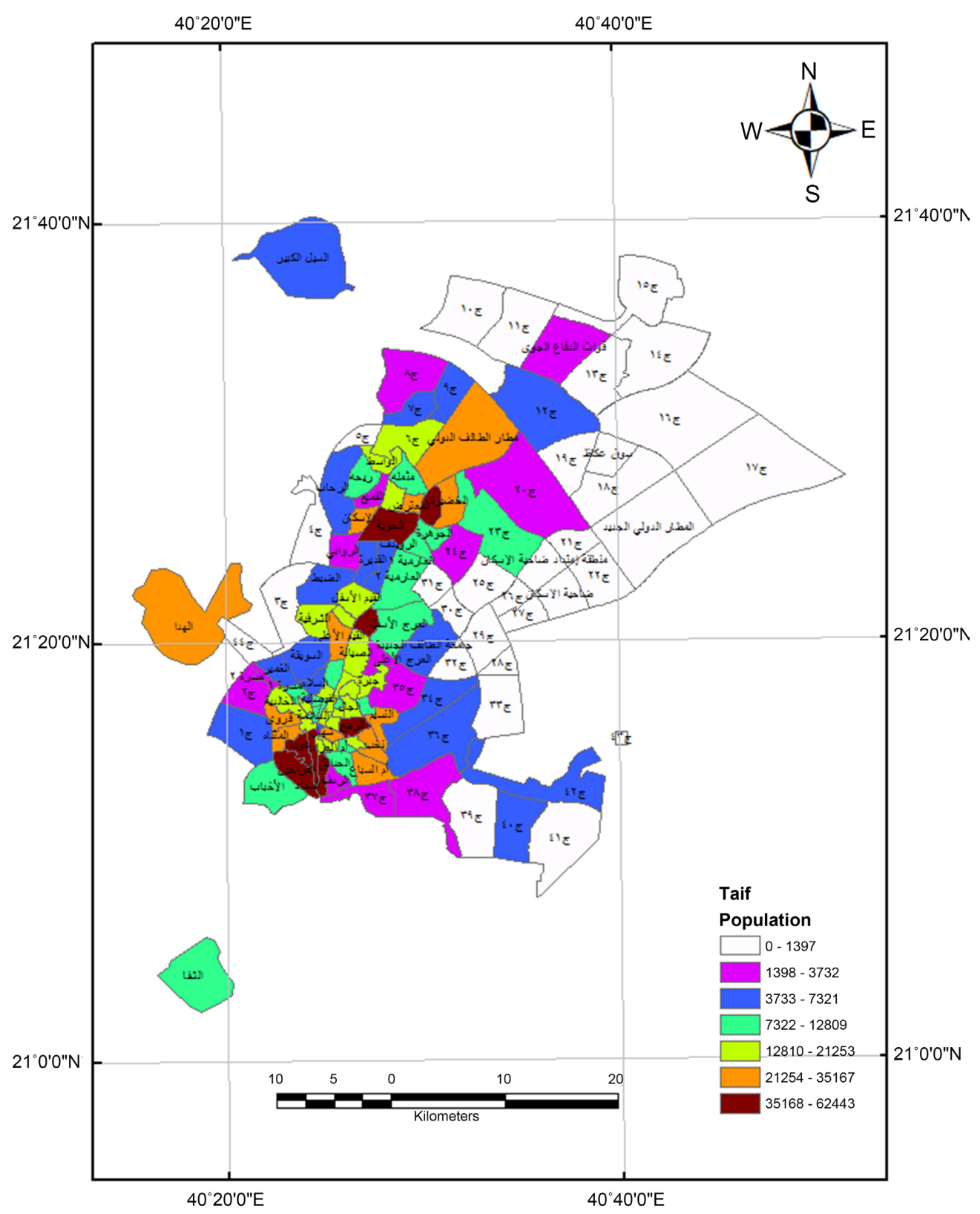

Figure 3. Population density. 


\subsection{Analysis}

This section describes the methodology to be used to analyze urban expansion in Taif to achieve the research objectives. Multi-temporal Landsat images for the year of 1990, 2002 and 2020 were checked to ensure the comprehensiveness of these images to cover the study period. These Multi-temporal Landsat images will used to create urban expansion map using ERDAS Imagine 2014 and ArcGIS 10.2. Details of the process are presented in subsequent sections.

\subsubsection{Landsat Image}

Satellite images of Taif city were downloaded from the United States Geological Surveying (USGS) website (www.earthexplorer.usgs.gov). These images are for different periods of time by Landsat 4,5 , and 8 satellites. Dates of acquisition of each year as well as the sensor name are as follows:

- Landsat 4 image, captured on 27/8/1990.

- Landsat 5 image, captured on 19/7/2002.

- Landsat 8 image, captured on 16/10/2020.

\subsubsection{Image Processing}

After obtaining satellite images for the study period, these images undergone preprocessing stages. In order to prepare the satellite images for analysis, interpretation, and classification various steps and processes are available. Numerous researchers and scientists have used different techniques to improve the quality of satellite images such as geometric correction, radiometric correction, enhancement, classification etc. [8] [9]. However, the processing methods depend on number of bands present in image, on the spatial and temporal properties of satellite image.

\subsubsection{Image Classification}

There are two types of classification techniques, that are widely used in the scientific community to analysis and assign land cover classes to pixels. They are supervised and unsupervised classifications which are used according to several criteria, conditions and use cases. In this study, we have used a supervised maximum likelihood classification to classify images of 1990, 2002 and 2020 by virtue of our knowledge of the studied area, which makes us avoid as much as possible the spectral problems in the image such as the spectral similarity between terrestrial objects and the weakness of the rays reflected or emitted from those objects as shown in Figure 4. In the process of classification, land use and land cover (LULC) were detected. The Landsat images were classified into three main categories, namely, urban area, green area, and space area as shown in Table 2.

\subsubsection{Accuracy Assessment}

Accuracy assessment is one of the most important final steps in classification process. In the general term, it is used for comparing the land cover classification results to geospatial data that are assumed to be true as Google earth or Google map. The purpose of accuracy assessment is to quantitatively assess how 
effectively the pixels were sampled into the correct land cover classes [10]. One of techniques used to assess the accuracy in the classification process is the Kappa coefficient, which generally used to measure the randomness of classification result the accuracy of image classifications.

Table 2. Land use land cover classified classes.

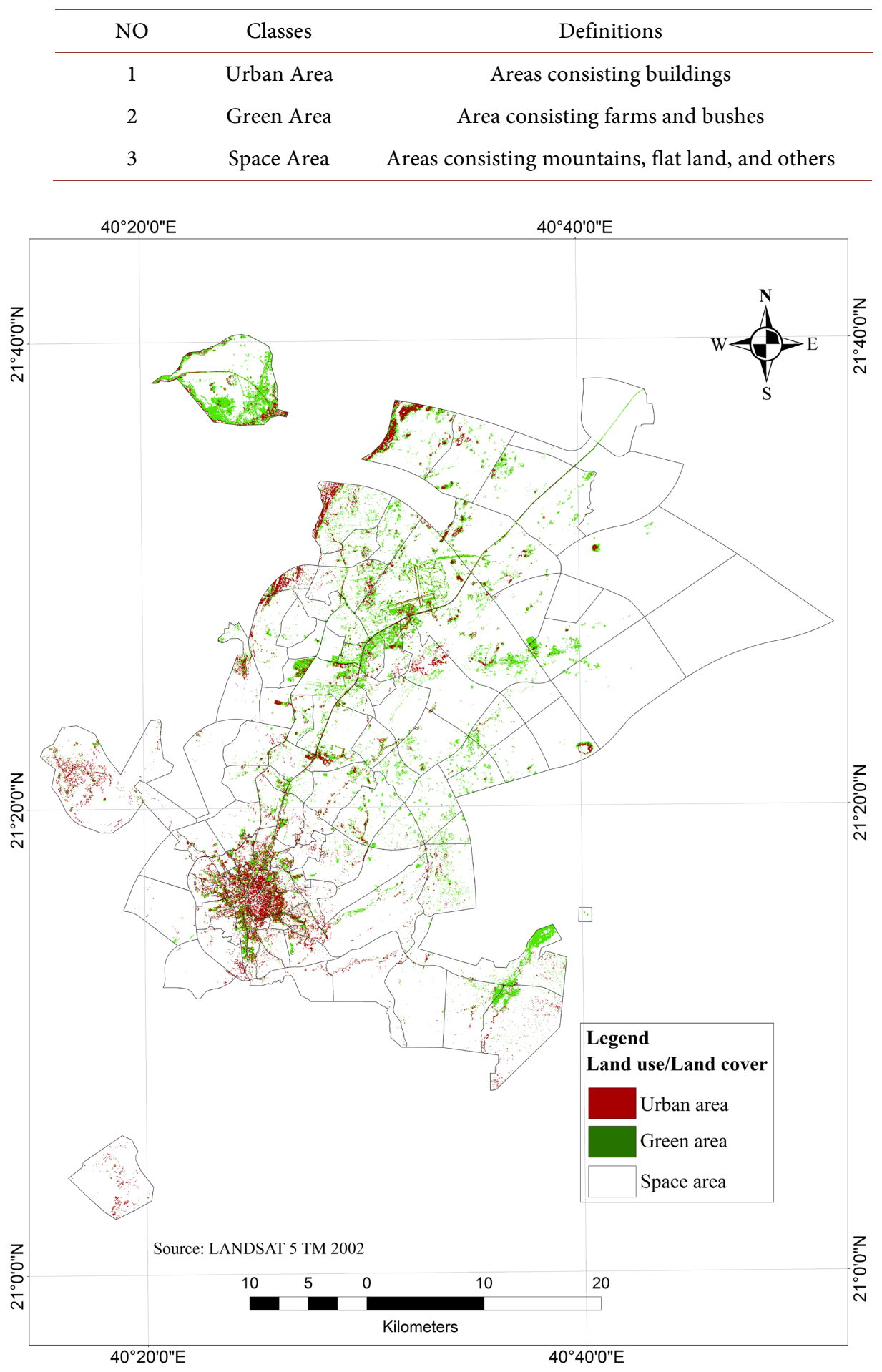

(a) 


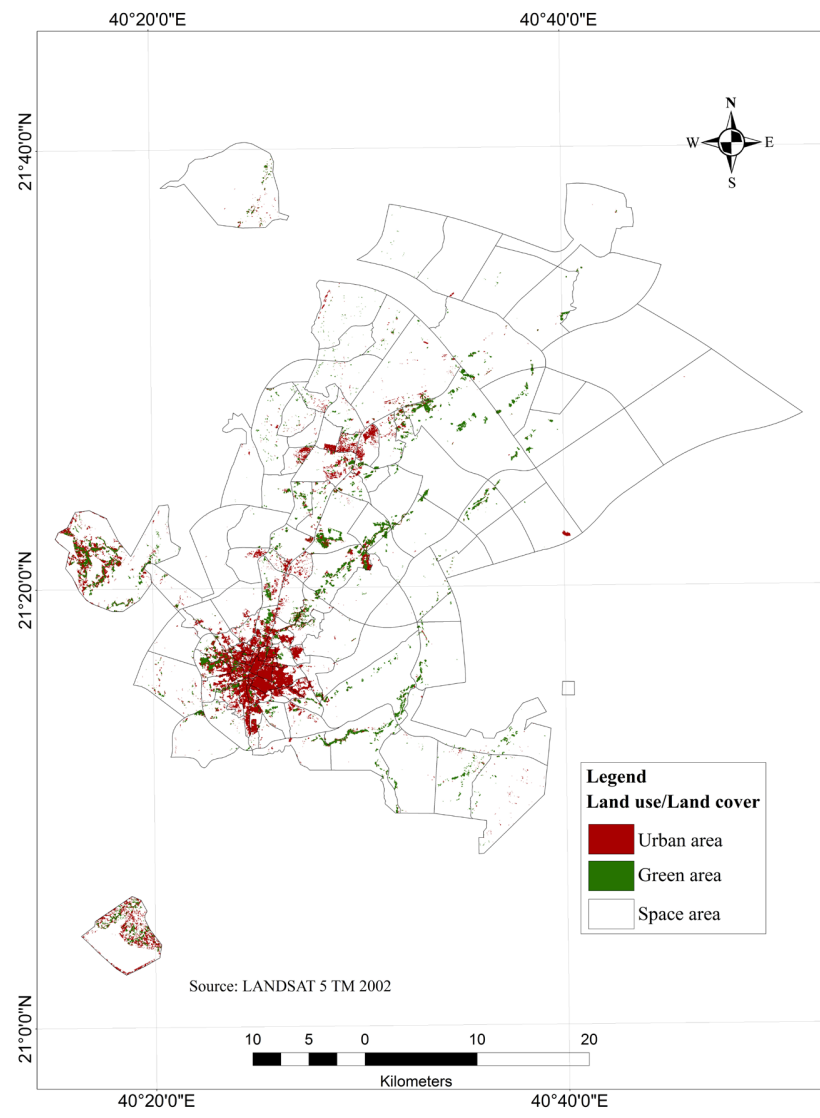

(b)

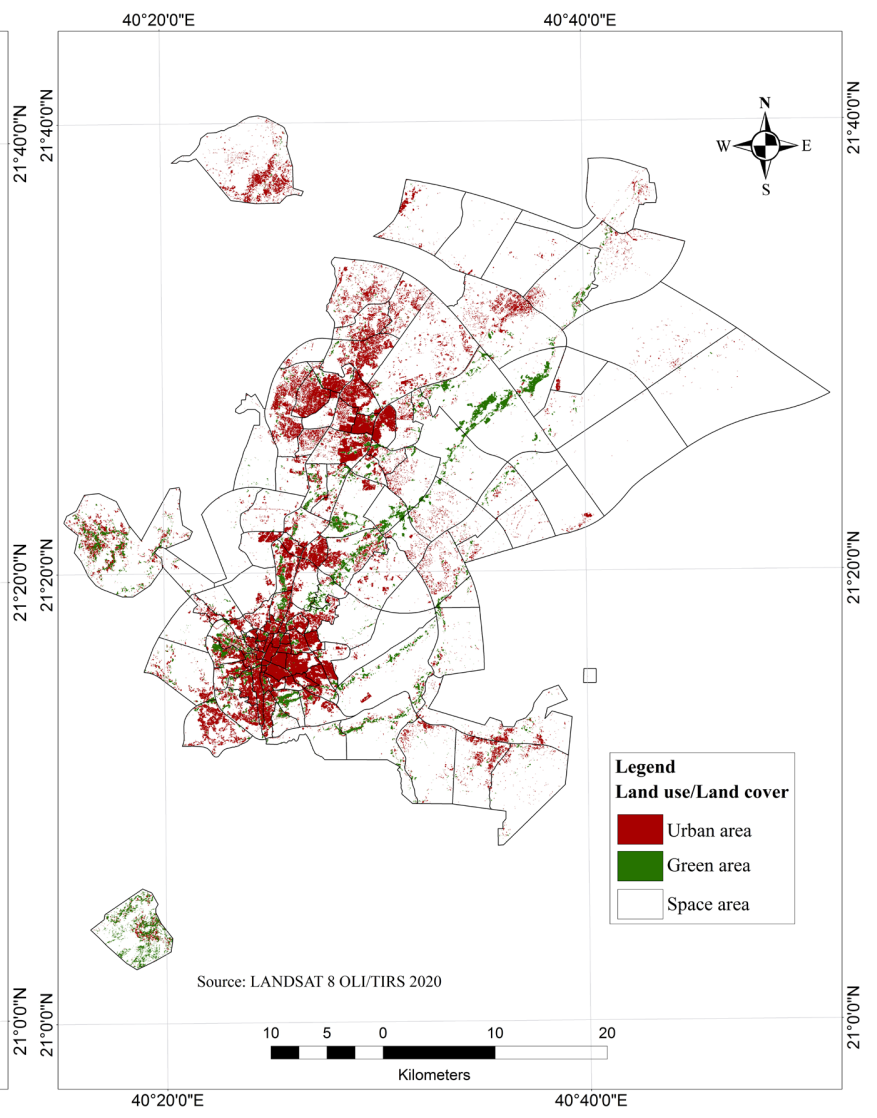

(c)

Figure 4. Supervised classification of 1990 (a), 2002 (b), and 2020 (c).

\section{Results and Discussions}

As a result of selecting pure training sites within each class, considering intra-class variability, and distributing training areas evenly over the study area, we were able to accurately classify the images. The overall accuracy of image of the 2020 Landsat 8 was $93.08 \%$, and Kappa coefficient was 0.891 . Classification of urban area had moderately high user accuracy and high producer accuracy. Green area had moderately high user and producer accuracy. Furthermore, space area had high user accuracy and moderately high producer accuracies of $100 \%$ and $87.1 \%$, respectively. Table 3 shows the derived error matrix.

\subsection{Land Use and Land Cover (LU/LC)}

Table 4 and Figure 5 show the area statistics and spatial distribution of the classified Landsat images from 1990, 2002, and 2020. LU/LC maps, in general, depict the geographical distribution of various land covers across the research area. While analyzing the land cover map for 1990, it can be seen that urban area class comprised of $2.02 \%$ of the total area, green areas composed of $3.75 \%$, and space areas class composed $94.23 \%$ of the study area. Similarly, the 2002 land cover map indicated an increase in the urban areas, which reach to $2.89 \%$ of the total area and a reduction in green areas and space areas of $3.08 \%$ and $94.03 \%$, respectively. 
Table 3. Error matrix of 2020 Landsat image.

\begin{tabular}{|c|c|c|c|c|c|c|}
\hline \multicolumn{7}{|c|}{ Classes } \\
\hline & Class & Urban Area & Green Area & Apace Area & Row Total & $\begin{array}{c}\text { User's } \\
\text { Accuracy }\end{array}$ \\
\hline \multirow{3}{*}{$\begin{array}{c}\text { Classified } \\
\text { data }\end{array}$} & Urban Area & 42 & 1 & 7 & 50 & 84 \\
\hline & Green Area & 0 & 25 & 1 & 26 & 96.15 \\
\hline & Space Area & 0 & 0 & 54 & 54 & 100 \\
\hline & Column Total & 42 & 26 & 62 & 130 & 278.15 \\
\hline & & 100 & 96.15 & 87.1 & $\begin{array}{c}\text { Overall } \\
\text { Accuracy }\end{array}$ & $93.08 \%$ \\
\hline & \multicolumn{2}{|c|}{ Kappa coefficient } & & & 0.891 & \\
\hline
\end{tabular}

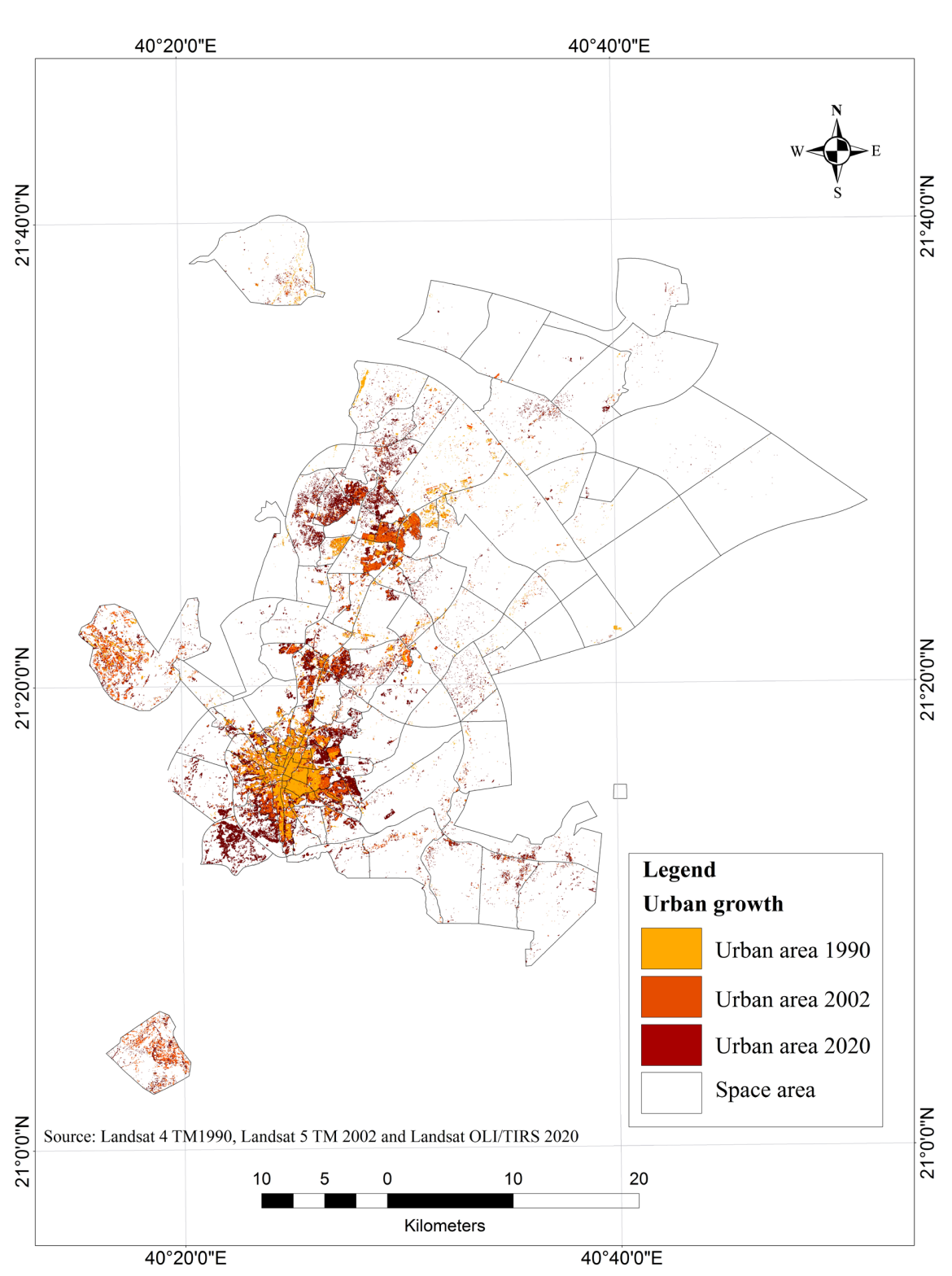

Figure 5. Classified land cover images of 1990, 2002 and 2020. 
Table 4. LU/LC information using percent cover and area extent.

\begin{tabular}{ccccccc}
\hline \multirow{2}{*}{ Land cove } & \multicolumn{2}{c}{1990} & \multicolumn{2}{c}{2002} & \multicolumn{2}{c}{2020} \\
\cline { 2 - 7 } & Area (ha) & $\%$ & Area (ha) & $\%$ & Area (ha) & $\%$ \\
\hline Urban Area & 17,809 & 2.02 & 25,502 & 2.89 & 38,257 & 4.34 \\
Green Area & 33,093 & 3.75 & 27,146 & 3.08 & 18,539 & 2.10 \\
Space Area & 831,420 & 94.23 & 829,710 & 94.03 & 825,520 & 93.56 \\
Total & & $100 \%$ & & $100 \%$ & & $100 \%$ \\
\hline
\end{tabular}

Furthermore, the classification result for the 2020 map showed an increase of urban areas of $4.34 \%$ and a reduction in the other land covers.

According to results, urban land greatly increased within 30 years. Urban growth cannot be greatly emphasized or explained without taking a closer look at land use. Table 5 shows that the urban land cover of the metropolitan area increased from $2.02 \%$ in 1990 to $4.34 \%$ in 2020 of the total area. In 2002, urban area increased by $52.4 \%$ to be 25,502 (ha) at $3.04 \%$ annual rate, and reached 38,257 (ha) in 2020 at an annual rate of $2.6 \%$. The results also indicate that the increase in urban areas amounted to $114.8 \%$ during the period from 1990 to 2020. This indicated that there has been a continued increment in urban growth, which supports the findings of Alqurashi and Kumar (2014) [11] [12], who found that Taif's urban land use has increase by 113\% from 1986 to 2013.

While the green area decreased from 33,093 (ha) in 1900 to 27,146 (ha) in 2002 , then 18,539 (ha) in 2020 , that shows the decrease by $44 \%$ over the past 30 years and at an annual rate of $1.95 \%$. There is a strong relationship between urban growth and green lands. This is an inverse relationship whereby the increase in urban growth leads to a decrease in green lands as shown in Table 5.

\subsection{Directions of Urban Expansion}

Through the cartographic treatment of the three images for the years 1990, 2002 and 2020, the study noted that the urban expansion of the city of Taif did not include all directions in the same way. As the expansion included the north and northeastern sides. However, there are several factors that influenced the determination of the direction of urban expansion, the most important factors are as follows:

\subsubsection{Topography Effect}

The topography of the area greatly affected the direction of urban expansion. The north and north-east sides have fairly flat slope, i.e., 0 to 25 degrees, which allows for construction and reconstruction. Unlike the southern and west sides, where there is rugged mountainous terrain that represents a natural obstacle to urban expansion. This indicated that topography has an effect on urban expansion which supports the findings of Alqurashi, Kumar, Al-Ghamdi [13], who found that elevation, slope and road distance had considerable results on the urban growth. 
Table 5. Relationship between urban and green areas.

\begin{tabular}{ccc}
\hline Year & urban growth & vegetative growth \\
\hline 1990 & 17,809 & 33,093 \\
2002 & 22,502 & 27,146 \\
2020 & 38,257 & 18,539 \\
Correlation coefficient R & \multicolumn{2}{c}{-0.980539842269745} \\
Coefficient of determination $\mathrm{R}^{2}$ & \multicolumn{2}{c}{0.961458382278375} \\
\hline
\end{tabular}

\subsubsection{Development Effect and Service Projects}

The northern side contains the old and new Taif Airport, Taif University (TU), and an important group of other government facilities and luxury shops that attract residents, and this is evident in Figure 6. On the other hand, the southern side, which provides residents only simple and seasonal services related to tourism on holidays, such as some game stores and the Taif cable car.

\subsubsection{Real Estate Reasons}

Due to the remoteness of the northern side from the original nucleus of the city of Taif, or the so-called old city center, the price of residential lands was appropriate and accessible to a wide category of citizens, especially during the period of the high price of oil in the world, from which the KSA benefited greatly, which was reflected on the purchasing power of the Saudi citizen. Furthermore, the role of the state in facilitating real estate loans for citizens who are eligible to get some financial support from a local bank for purchasing and reconstruction of land.

\subsection{Population Increases and Urban Growth}

Taif has experienced a positive annual urban growth rate of $2.5 \%$ over the last 30 years. The urban growth can be attributed to the natural increase in population. The population of Taif city has increased from 381,000 in 1990 to 689,000 in 2020, which the expected census stats. Furthermore, young people who live on the outskirts of Taif area strive for a better lifestyle, education and employment; therefore, they tend to migrate from rural areas to Taif. Given the time period considered in this study, a correlation between population increase and urban growth can be revealed. Population growth along with economic diversification is the main driver for urban growth in the any city. In addition, more people are being drawn to urban areas by push and pull factors. Therefore, the increase of Taifs population over the years has contributed to the city's urban expansion, i.e., increasing the number of residents resulted in an expansion of urban land cover and urban extension. The growth in the number of people living in towns and cities is known as urbanization. Urbanization happens primarily as a result of people migrating from rural to urban areas, resulting in an increase in the number of the urban population and the size of urban areas. Land use, economic activity, and culture all alter as a result of population fluctuations. Historically, 


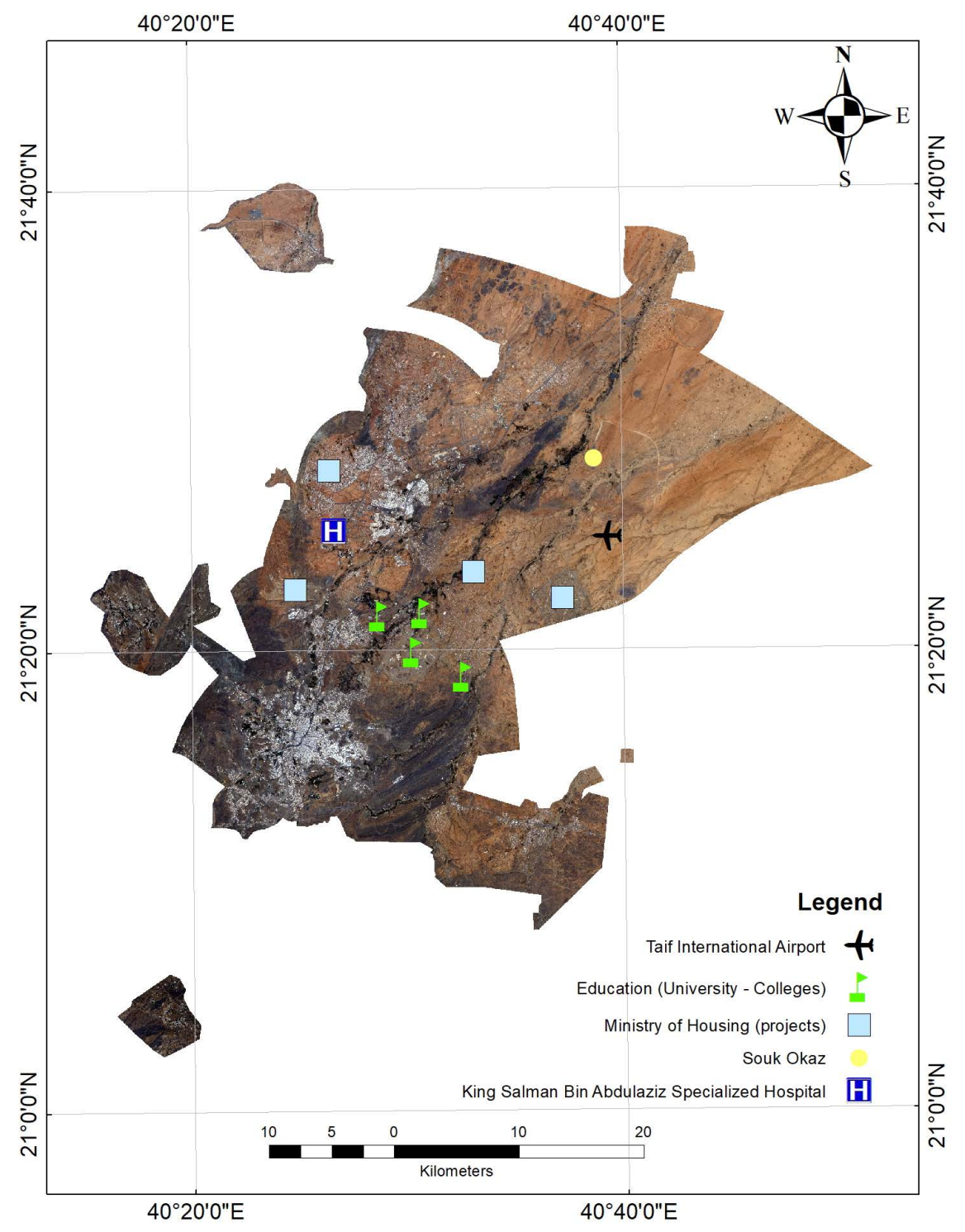

Figure 6. Location of development and service projects.

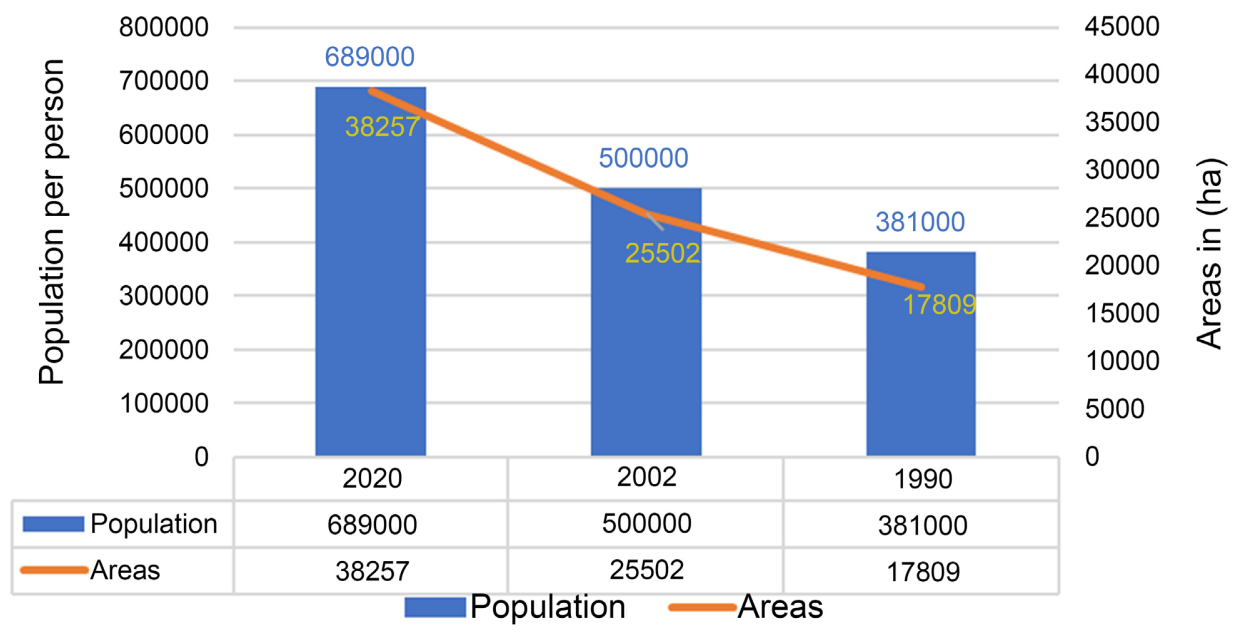

Figure 7. Trend of population and built-up areas for Taif city. 
urbanization has been linked to considerable economic and social changes. Therefore, there is a direct relationship between the number of population and urban expansion; in other words, an increase in the population leads to an increase in urban expansion (Figure 7).

\section{Conclusions and Recommendations}

Although urbanization creates many economic opportunities, it exerts pressure on different ecosystems. However, establishing a spatial pattern and planning the sites of new constructions is critical in assisting city planners in managing the hazards associated with sprawl in order to maintain human and environmental sustainability. This study came to identify the amount of urban expansion and its trends in the city of Taif through the achievement of the objectives of the study previously mentioned, which were successfully achieved.

The results showed that over the last 30 years, urban land cover has increased by 20,448 (ha) or $114.8 \%$ at a rate of $2.5 \%$ per year, indicating a continuing increase in urban growth. The analysis revealed that; 1) the southern and western sides are mountainous and rugged areas that represent a natural obstacle to urban expansion, and construction in them is at a high cost. On the other hand, the Northern and Northeastern sides have somewhat flat terrain, which helps reduce the cost of construction, especially after the rise in the prices of building materials in general in recent years. The slope is one of the factors that did not help the urban expansion towards the south and west of Taif, as it is not allowed to build in areas where the slope is more than $30 \%$. And 2) government support by facilitating real estate loans for citizens through the former real estate bank, which had a major role in urban expansion. Also, the Ministry of Housing's initiatives in Taif city included four housing projects on a total area of around 19 $\mathrm{km}^{2}$. There are 16,319 housing units in these developments. This is further evidence of the government's support for urban expansion. In this period, most development and service projects in Taif, such as education, health, and services (Taif airport, Taif University, housing projects, etc.) are located in the North and North-east of the city of Taif. As a result, urban expansion was influenced by these services as a pull factor.

\section{Future Prospects and Recommendations}

The observed trajectory of urban expansion in Taif over the last 30 years has necessitated additional research. The future study may include a prediction model that can estimate the extent of urban expansion over the next 30 years. It may be used to educate planning authorities about the level of urban expansion for which they should prepare. The following future prospects and recommendations can be made based on this research:

- Due to urban expansion in a specific direction, Taif will faces many problems such as traffic congestion, drinking water shortages, sewerage disposal issues, and a slew of other environmental and socioeconomic issues that cannot be 
handled without addressing issues related to urban development.

- To better understand the causes and implications of urban expansion, future research might include aspects such as land value, education, quality of life, and economic activities.

- Planning authorities and those related to urban development should take the topographic factor into consideration, and do not allow construction in valleys to maintain safety.

- Supporting the trend towards vertical construction, such as residential apartments, and moving away from horizontal construction, such as residential villas that consume larger areas.

- For the formulation of adequate plans and bi-laws for city planning and development, environmental factors, socio-economic prospects, and land values should be combined.

- Further environmental impact such as, water pollution, air pollution, ecological imbalance, and temperature rise can be studied in response to growth of urban in Taif.

\section{Conflicts of Interest}

The authors declare no conflicts of interest regarding the publication of this paper.

\section{References}

[1] Alahmadi, M. and Atkinson, P.M. (2019) Three-Fold Urban Expansion in Saudi Arabia from 1992 to 2013 Observed Using Calibrated DMSP-OLS Night-Time Lights Imagery. Remote Sensing, 11, 2266. https://doi.org/10.3390/rs11192266 https://www.mdpi.com/2072-4292/8/10/838

[2] PopulationStat (2020) Taif, Saudi Arabia Population. https://populationstat.com/saudi-arabia/taif

[3] Essa Ali Alawi (2021) History of Taif. https://taifchamber.org.sa/pages/\%D9\%86\%D8\%A8\%D8\%B0\%D8\%A9-\%D8\%B9\% D9\%86-\%D8\%A7\%D9\%84\%D8\%B7\%D8\%A7\%D8\%A6\%D9\%81/18

[4] Yan, Z., Teng, M., He, W., Liu, A., Li, Y. and Wang, P. (2019) Impervious Surface Area Is a Key Predictor for Urban Plant Diversity in a City Undergone Rapid Urbanization. Science of The Total Environment, 650, 335-342. https://doi.org/10.1016/j.scitotenv.2018.09.025

[5] Ministry of Municipal and Rural Affairs MMRA (2019) Taif City Profile. https://unhabitat.org/sites/default/files/2020/03/taif.pdf

[6] The Saudi Profile (2021) Taif City Profile. http://www.the-saudi.net/saudi-arabia/taif/Taif\%20-\%20Saudi\%20Arabia.htm

[7] Hikersbay (2021) Climate Conditions of Taif. http://hikersbay.com/climate-conditions/saudiarabia/taif/alzrwf-almnakhyh-fy-alta ef.html?lang=ar

[8] Pran (2019) Digital Image Processing Tutorial-Introduction to Erdas Imagine Software. https://www.gisoutlook.com/2019/07/image-processing-software-erdas-imagine.ht $\underline{\mathrm{ml}}$ 
[9] Gan, W.S. (2020) Digital Image Enhancement. In Signal Processing and Image Processing for Acoustical Imaging, Springer, Singapore.

https://doi.org/10.1007/978-981-10-5550-8_12

https://link.springer.com/chapter/10.1007/978-981-10-5550-8 12\#citeas

[10] Rwanga, S.S. and Ndambuki, J.M. (2017) Accuracy Assessment of Land Use/Land Cover Classification Using Remote Sensing and GIS. International Journal of Geosciences, 8, 611-622. https://doi.org/10.4236/ijg.2017.84033

[11] Alqurashi, A.F. and Kumar, L. (2014) Land Use and Land Cover Change Detection in the Saudi Arabian Desert Cities of Makkah and Al-Taif Using Satellite Data. Advances in Remote Sensing, 3, 106-119. https://doi.org/10.4236/ars.2014.33009

[12] Alqurashi, A.F., Kumar, L. and Sinha, P. (2016) Urban Land Cover Change Modelling Using Time-Series Satellite Images: A Case Study of Urban Growth in Five Cities of Saudi Arabia. Remote Sensing, 8, 838. https://doi.org/10.3390/rs8100838

[13] Alqurashi, A.F., Kumar, L. and Al-Ghamdi, K.A. (2016) Spatiotemporal Modeling of Urban Growth Predictions Based on Driving Force Factors in Five Saudi Arabian Cities. ISPRS International Journal of Geo-Information, 5, 139.

https://doi.org/10.3390/ijgi5080139 